\section{Mérida conmemora el centenario de excavaciones arqueológicas}

1910-2010. La capital extremeña celebra este año su centenario desde que se iniciaran los primeros trabajos arqueológicos en la ciudad. Con este motivo se ha organizado un programa de actividades conmemorativas con el que al mismo tiempo se pretende rendir homenaje al conjunto de arqueólogos españoles responsables de la labor realizada durante todos estos años de excavaciones. Publicaciones, talleres, exposiciones fotográficas... y un congreso internacional para finales de año son algunas de las actividades previstas con el firme deseo, según los responsables del programa, "de dar a conocer a toda la sociedad la relevancia histórica del yacimiento arqueológico y su vinculación diaria con la ciudad actual y con todos los emeritenses".

Con motivo de la conmemoración del centenario del inicio de los trabajos arqueológicos en el teatro y anfiteatro romanos, considerado el primer proyecto arqueológico de contenido científico realizado en la ciudad, pretendemos desarrollar una serie de actividades de difusión científica que tengan como hilo conductor dar a conocer la historia de la arqueología emeritense a lo largo de estos cien años.

Es, no cabe duda, una buena oportunidad para unir en un mismo proyecto a las distintas instituciones vinculadas a la gestión, investigación y difusión del yacimiento arqueológico emeritense en

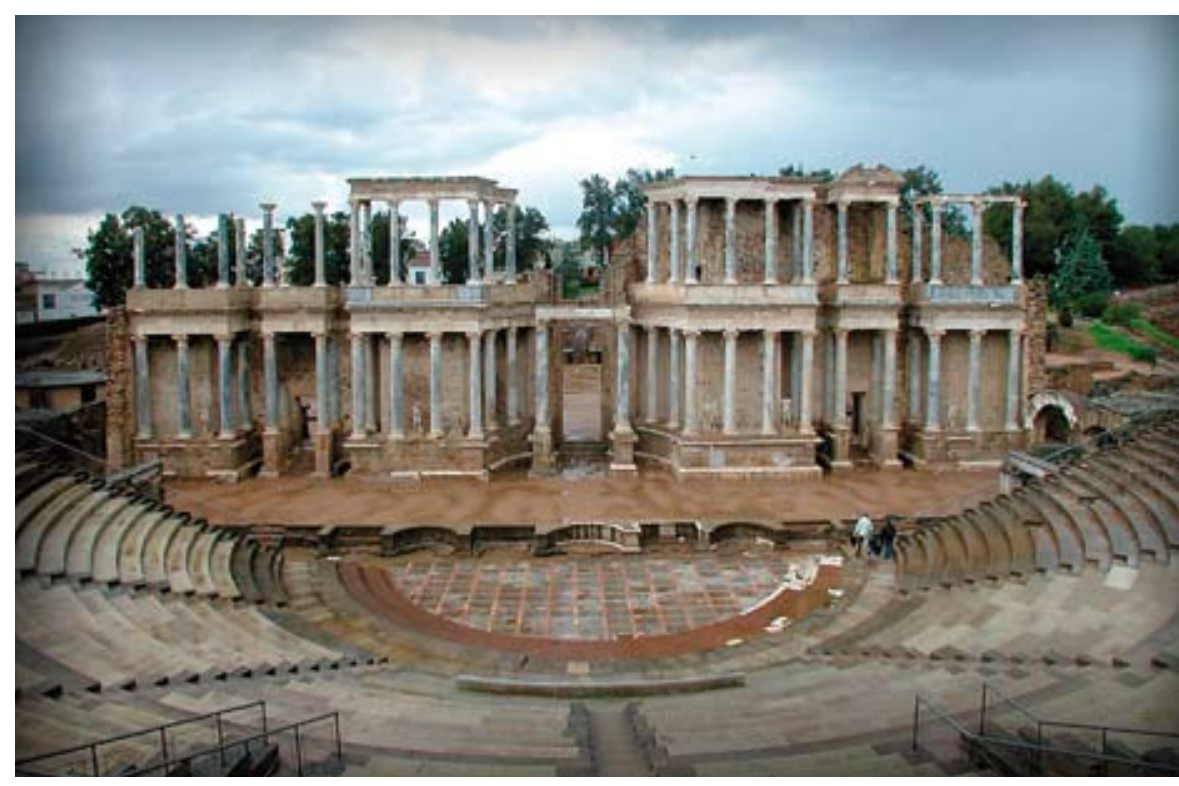

Frente escénico del teatro romano de Mérida en la actualidad.

Foto: Ceferino López. Fuente: Fondo Consorcio de Mérida histórica del yacimiento arqueológico, los hitos fundamentales que lo han convertido en un referente internacional y la vinculación diaria con la ciudad actual y con todos los emeritenses.

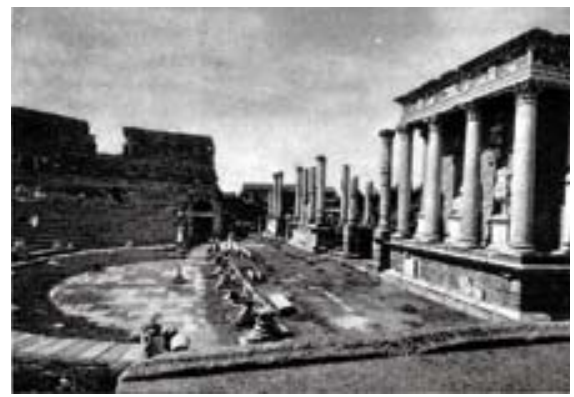

La escena del teatro romano de Mérida tras su restauración del primer orden en los años 30. Fuente: Fondo Consorcio de Mérida

un evento que pretende sea compartido por el mayor número de historiadores y arqueólogos que, con su trabajo, han contribuido al conocimiento del pasado histórico de nuestra ciudad.

El objetivo es hacer de 2010 un año especialmente importante para Mérida y su yacimiento arqueológico; un año en el que toda la actividad cultural y patrimonial tenga como hilo conductor esta conmemoración.

Este programa de actividades pretende dar a conocer a toda la sociedad, no sólo a la comunidad científica, la relevancia

Pero esta conmemoración también debe convertirse en un escaparate mundial para Mérida, Ciudad Patrimonio de la Humanidad, por lo que algunas de las actividades poseerán un carácter internacional que se pasearán por los principales escenarios culturales del mundo.

A lo largo de los años 2008 y 2009 se han llevado a cabo diferentes iniciativas (exposiciones temporales, publicaciones, programas de público, etc.) que han preparado el camino para este año 2010, en el que se realizarán los principales actos conmemorativos que finalizarian con la inauguración el 10 de septiembre (dia y mes en la que se iniciaron las excavaciones arqueológicas en el teatro romano en 1910) de una gran exposición sobre estos cien años de arqueología en Mérida, a celebrar en el Museo Nacional de Arte Romano y el teatro romano que se trasladará posteriormente a diferentes lugares del mundo. Del mismo modo llevaremos a cabo en el mes de noviembre un congreso internacional que abordará el estado de la cuestión del conocimiento del yacimiento arqueológico emeritense desde el punto de vista diacrónico.

José María Álvarez Martínez Pedro Mateos Cruz

Directores científicos del programa 